\title{
Validation of ENVISAT/SCIAMACHY columnar methane by solar FTIR spectrometry at the Ground-Truthing Station Zugspitze
}

\author{
R. Sussmann ${ }^{1}$, W. Stremme ${ }^{1}$, M. Buchwitz ${ }^{2}$, and R. de Beek ${ }^{2}$ \\ ${ }^{1}$ IMK-IFU, Forschungszentrum Karlsruhe, Garmisch-Partenkirchen, Germany \\ ${ }^{2}$ Institute of Environmental Physics (iup), University of Bremen FB1, Bremen, Germany \\ Received: 27 January 2005 - Published in Atmos. Chem. Phys. Discuss.: 13 April 2005 \\ Revised: 1 July 2005 - Accepted: 5 September 2005 - Published: 20 September 2005
}

\begin{abstract}
Methane total-vertical column retrievals from ground-based solar FTIR measurements at the Permanent Ground-Truthing Station Zugspitze $\left(47.42^{\circ} \mathrm{N}, 10.98^{\circ} \mathrm{E}\right.$, $2964 \mathrm{~m}$ a.s.l.), Germany are used to validate column averaged methane retrieved from ENVISAT/SCIAMACHY spectra by WFM-DOAS (WFMD) version 0.4 and 0.41 for 153 days in 2003. Smoothing errors are estimated to be below $0.10 \%$ for FTIR and $0.14 \%$ for SCIAMACHY-WFMD retrievals and can be neglected for the assessment of observed bias and day-to-day-scatter. In order to minimize the altitude-difference effect, dry-air column averaged mixing ratios $\left(\mathrm{XCH}_{4}\right)$ have been utilized. From the FTIRtime series of $\mathrm{XCH}_{4}$ an atmospheric day-to-day variability of $1 \%$ was found, and a sinusoidal annual cycle with $\mathrm{a} \approx 1.6 \%$ amplitude. To obtain the WFMD bias, a polynomial fitted to the FTIR series was used as a reference. The result is WFMD v0.4/FTIR $=1.008 \pm 0.019$ and WFMD $\mathrm{v} 0.41 / \mathrm{FTIR}=1.058 \pm 0.008$. WFMD v0.41 was significantly improved by a time-dependent bias correction. It can still not capture the natural day-to-day variability, i.e., the standard deviation calculated from the daily-mean values is $2.4 \%$ using averages within a $2000-\mathrm{km}$ radius, and $2.7 \%$ for a $1000-$ $\mathrm{km}$ radius. These numbers are dominated by a residual timedependent bias in the order of 3\%/month. The latter can be reduced, e.g., from $2.4 \%$ to $1.6 \%$ as shown by an empirical time-dependent bias correction. Standard deviations of the daily means, calculated from the individual measurements of each day, are excluding time-dependent biases, thus showing the potential precision of WFMD daily means, i.e., $0.3 \%$ for a $2000-\mathrm{km}$ selection radius, and $0.6 \%$ for a $1000-\mathrm{km}$ selection radius. Therefore, the annual cycle as well as possibly the day-to-day variability could be captured under the prerequisite of further advanced time-dependent bias corrections, or the use of other channels, where the icing issue is less prominent.
\end{abstract}

Correspondence to: R. Sussmann

(ralf.sussmann@imk.fzk.de)

\section{Introduction}

The atmospheric trace species methane $\left(\mathrm{CH}_{4}\right)$ contributes by $15 \%$ to the anthropogenic greenhouse forcing, and has recently been included into the list of the so called "Kyoto gases". It has thus become mandatory to better understand and monitor its spatiotemporal distribution on a global and centennial scale. In particular, the locations and strengths of the $\mathrm{CH}_{4}$ sources are not sufficiently quantified yet (IPCC, 2001). An obstacle for the quantification of surface sources is that measurements of small variations on top of a large background of this well-mixed gas are required. Therefore, measurements with both high precision and global coverage are needed.

High-precision measurements of in-situ mixing ratios are realized by surface-sampling sites of the GAW (Global Atmosphere Watch) and NOAA/CMDL (National Oceanic and Atmospheric Administration Climate Monitoring and Diagnostics Laboratory) networks. By the inverse modeling of these in-situ measurements the global atmospheric $\mathrm{CH}_{4}$ cycle has been characterized and the average uncertainties of $\mathrm{CH}_{4}$ source magnitudes could be reduced by more than one third (Hein et al., 1997).

Ground-based solar FTIR (Fourier Transform Infrared) spectrometry sites operated within the NDSC (Network for the Detection of Stratospheric Change) are yielding vertical total columns of $\mathrm{CH}_{4}$. The Zugspitze FTIR is a so called Primary-Status instrument within the NDSC, which certifies both operationality and data quality on a highest level. These ground-based total-column measurements are crucial for the validation of the upcoming satellite missions dedicated to the measurement of greenhouse gases, and are likely to become important constraints on the geographic and temporal distribution of $\mathrm{CH}_{4}$ sources and sinks in the future.

Satellite-borne remote sounders are also providing total columns and have the potential to add the required information on the global distribution of $\mathrm{CH}_{4}$ to the highly precise ground-based networks, but strongly rely upon careful

(C) 2005 Author(s). This work is licensed under a Creative Commons License. 
ground-truthing. The first global maps of $\mathrm{CH}_{4}$ columns have been retrieved from IMG/ADEOS thermal infrared (TIR) nadir spectra (Kobayashi et al., 1999). The results show qualitatively the expected variability, for example the NorthSouth hemispheric gradient (Clerbaux et al., 2003). The $\mathrm{CH}_{4}$ amounts retrieved from TIR nadir observations are relatively insensitive to changes within the lower troposphere, however.

Meanwhile, another satellite instrument has achieved the potential to retrieve global information on $\mathrm{CH}_{4}$, i.e., the Scanning Imaging Absorption Spectrometer for Atmospheric CHartographY (SCIAMACHY), which is a UV/visible/nearinfrared spectrometer onboard ENVISAT launched in 2002 (Bovensmann et al., 1999). Due to the near-infrared (NIR) spectral domain the SCIAMACHY nadir measurements of $\mathrm{CH}_{4}$ are highly sensitive to concentration changes at all altitude levels, including the boundary layer (see Sect. 3).

In this paper we focus on the validation of the SCIAMACHY scientific total-column product retrieved at the University of Bremen by the Weighting Function Modified DOAS (WFMD) algorithm (Buchwitz and Burrows, 2004; Buchwitz et al., 2005a, b), which utilizes an iterative spectral fitting by scaling of an US-standard a priori profile. $\mathrm{CH}_{4}$ has been retrieved from the $2265-2280 \mathrm{~nm}$ spectral region. Simultaneously, oxygen $\left(\mathrm{O}_{2}\right)$ columns have been retrieved from the oxygen A band (around $760 \mathrm{~nm}$ ). This enables the dry-air column averaged mixing ratio, denoted as $\mathrm{XCH}_{4}$, to be determined: $\quad \mathrm{XCH}_{4}:=\mathrm{CH}_{4}$-column $/ \mathrm{O}_{2}$-column $\times 0.2095$, where 0.2095 is the $\mathrm{O}_{2}$ mixing ratio of dry air. This normalization is a means of significantly improving the attainable measurement precision, because many systematic errors are common to the $\mathrm{CH}_{4}$ and $\mathrm{O}_{2}$ spectrometric retrievals, respectively, and thus cancel out (e.g., errors in pressure or zenith angle are propagating in a similar way to the retrieved columns of $\mathrm{CH}_{4}$ and $\mathrm{O}_{2}$ ). Our validation study refers to version 0.4 of the WFMD product 2003 data set, that has been released via the internet on 6 September 2004, including all consolidated SCIAMACHY level-1B products available for 2003, i.e., 153 days from the time period January 2003-October 2003. Additionally, we validate the version $0.41 \mathrm{XCH}_{4}$ data update, released on 30 September 2004, which includes an a-posteriori time-dependent bias correction, based on a channel-8 throughput analysis. Our study is the first validation of this (WFMD version 0.41) promising attempt to compensate for the time-dependent slit function changes due to the SCIAMACHY-channel 8 ice-build up. $\mathrm{XCH}_{4}$ version 0.41 also utilizes a normalization by $\mathrm{CO}_{2}$ rather than $\mathrm{O}_{2}$, which has the advantage of being retrieved in a spectral domain that is spectrally more closely neighbored to the target species). The SCIAMACHY $\mathrm{CH}_{4}$ scientific product plays a key role for the users community, since there has been no operational product for $\mathrm{CH}_{4}$ released by ESA yet.

An initial comparison of WFMD $\mathrm{CH}_{4}$ retrievals to global models showed that the measured column amounts agree with the model columns within a few percent. For individual measurements the standard deviations of the difference with respect to the models were found to be in the range of 100200 ppbv (5-10\%) for $\mathrm{XCH}_{4}$ (Buchwitz et al., 2005a). Early characterization studies of SCIAMACHY scientific products have also been presented at the Second Workshop on the Atmospheric Chemistry Validation of ENVISAT (ESA, 2004).

In this paper we want to promote the validation and maturation of SCIAMACHY $\mathrm{XCH}_{4}$ by comparing the WFMD v.04 and v0.41 retrievals to the ground-based correlative solar FTIR data of the clean air site Zugspitze. The goal of this paper is i) to thereby assess the overall bias of WFMD v0.4 and 0.41 , ii) characterize the time-dependent bias (ice issue) in detail, in particular the intended effect from the version 0.4 to 0.41 update, and ii) to address the question, to which degree the precision of the WFMD retrievals allows to reflect the true atmospheric variability of $\mathrm{CH}_{4}$ in a realistic manner - both for the version 0.41 at hand, and under the assumption that the problem of time-dependent bias could be further reduced in future WFMD-data updates.

\section{The correlative ground-data set from Zugspitze solar FTIR}

Validation is performed using the ground-based data that are being recorded by the NDSC-Primary Status solar FTIR instrument at the Zugspitze $\left(47.42^{\circ} \mathrm{N}, 10.98^{\circ} \mathrm{E}, 2964 \mathrm{~m}\right.$ a.s.l.) continuously. The Zugspitze-FTIR instrument and retrievalset up has been described in detail elsewhere (Sussmann et al., 1997; Sussmann, 1999). Briefly, a high-resolution Bruker IFS 120 HR Fourier Transform Spectrometer is operated with an actively controlled solar tracker, and liquidnitrogen cooled MCT ( $\mathrm{HgCdTe})$ and InSb detectors.

The Zugspitze $\mathrm{CH}_{4}$ total columns are retrieved by using non-linear least squares spectral fitting software (SFIT) initially developed at NASA Langley Research Center (Rinsland et al., 1984). For the $\mathrm{CH}_{4}$ total-column retrievals we applied a strong smoothness constraint based upon a VMR a priori profile obtained from balloon-borne FTIR measurements (provided by G.C. Toon, JPL/NASA). We have chosen this conservative approach for the validation purpose of this paper, i.e., we are not performing a full profile retrieval (e.g., via optimal estimation). This is because there are still unresolved spectroscopic problems for $\mathrm{CH}_{4}$, like line mixing, that can propagate into erroneous profiles retrievals via the forward model, leading to subsequent errors in the retrieved columns. This effect is minimized by applying a strong smoothness constraint to the retrievals. The HITRAN-2000 molecular line parameters compilation was used (Rothmann et al., 2003), and daily p-T-profiles from the Munich radio sonde station (located $80 \mathrm{~km}$ to the north of the Zugspitze) have been utilized.

For the $\mathrm{CH}_{4}$ column retrievals two different spectral domains from routine-measurement operations were utilized, i.e., a MCT-detector domain micro-window at 
Table 1. Statistics of $\mathrm{XCH}_{4}$ data scatter for FTIR and WFMD v0.41 measurements and time periods as indicated in Fig. 5. The index for the number of measurement days is $i$. First column: $\mathrm{AV}_{i}\left(n_{i}\right)$, i.e., average of the numbers $n_{i}$ of individual measurements during each measurement day. Second column: $\operatorname{AV}_{i}\left(\sigma_{i}\right)$, i.e., average of the "single-value standard deviations" calculated from the individual measurements for the different days. 3rd column: $\mathrm{AV}_{i}\left(\sigma_{i} / \mathrm{sqrt}\left(n_{i}\right)\right)$, i.e., average of the "standard deviations of the daily mean values" calculated from the individual measurements for the different days. 4th column: Standard deviations of daily means calculated from the daily-means data sets as shown in Fig. 5a, i.e., normalized to the annual cycle (polynomial fit to FTIR). 5th column: Standard deviations of daily means calculated from the daily-means data sets as shown in Fig. 5b, i.e., after applying an empirical time-dependent bias-correction (polynomial fit to WFMD v0.41). SCIAMACHY data were taken within a 2000-km pixel-selection radius around the Zugspitze for each day ("SCIA 2000"), and a 1000-km selection radius ("SCIA 1000"), respectively.

\begin{tabular}{lccccc}
\hline & $\mathrm{AV}_{i}\left(n_{i}\right)$ & $\mathrm{AV}_{i}\left(\sigma_{i}\right)$ & $\mathrm{AV}_{i}\left(\sigma_{i} / \mathrm{sqrt}\left(n_{i}\right)\right)$ & $\begin{array}{c}\sigma \text { of daily means } \\
\text { corrected for } \\
\text { ann. cycle (Fig. 5a) }\end{array}$ & $\begin{array}{c}\sigma \text { of daily means incl. } \\
\text { empirical time-dependent } \\
\text { bias correction (Fig. 5b) }\end{array}$ \\
\hline Zugspitze FTIR & 12.3 & $1.3 \%$ & $0.4 \%$ & $1.0 \%$ & - \\
SCIA 2000 & 249 & $5.2 \%$ & $0.3 \%$ & $2.4 \%$ & $1.6 \%$ \\
SCIA 1000 & 85 & $5.4 \%$ & $0.6 \%$ & $2.7 \%$ & $2.4 \%$ \\
\hline
\end{tabular}

$1201.80-1202.65 \mathrm{~cm}^{-1}$, (859 spectra recorded on 133 measurement days in 2003; each spectrum resulted from integrating 8 interferometric scans with a 250 -cm optical path difference within $20 \mathrm{~min}$ ) and an InSb-detector domain microwindow at $2835.55-2835.85 \mathrm{~cm}^{-1}$ (781 spectra recorded on 133 measurement days in 2003; each spectrum resulted from 5 scans with a maximum optical path difference of 175 $\mathrm{cm}$ integrated within $10 \mathrm{~min}$ ). I.e., on average 6.5 MCTspectra and $5.8 \mathrm{InSb}$ spectra were recorded per day, yielding $6.5+5.8=12.3$ retrieved columns per day. The accuracies and precisions for $\mathrm{CH}_{4}$ vertical-column retrievals from single ground-based FTIR measurements are well characterized and understood and have been estimated from sensitivity studies to be below $6.5 \%$ and $2.5 \%$, respectively, see, e.g., Zander et al. (1989). The actual numbers depend somewhat on changing geophysical parameters like the actual solar zenith angle. Daily mean columns were calculated using the arithmetic mean of the individual columns. From the above error numbers the precision of a daily-mean column from our FTIR retrievals is estimated to be below $2.5 \% / \mathrm{sqrt}(12.3)=0.7 \%$. We will show in Sect. 4.2 .1 below, that we find an even smaller number of $0.4 \%$ for the precision of a daily mean $\mathrm{XCH}_{4}$ columns derived directly from our real FTIR measurements.

We calculated Zugspitze $\mathrm{XCH}_{4}$, i.e., air-column averaged mixing ratios for the validation purpose of this paper by dividing the FTIR $\mathrm{CH}_{4}$ columns by the air columns calculated from the daily radio soundings. Note that alternatively, other authors have used for the ground-based retrievals a normalization to $\mathrm{O}_{2}$ columns measured by FTIR at the same time (Washenfelder et al., 2003), i.e., an analogous approach as described for the satellite retrievals above. On the one side this helps to significantly improve the precision. On the other hand, this increases the uncertainties in the absolute $\mathrm{XCH}_{4}$ values due to additional errors from the $\mathrm{O}_{2}$ spectroscopic parameters propagating into the result.

\section{Validation approach}

First we focus on investigating the bias of absolute $\mathrm{XCH}_{4}$ values. The retrieval of WFMD version $0.4 \mathrm{XCH}_{4}$ includes an empirical column scaling factor, i.e., an $\mathrm{O}_{2}$ column scaling factor or 0.85 (no scaling factor for $\mathrm{CH}_{4}$ ), which will be validated. Version $0.41 \mathrm{XCH}_{4}$ data include a time-dependent bias correction in order to account for the icing issue of SCIAMACHY channel 8, and a normalization to $\mathrm{CO}_{2}$ instead of $\mathrm{O}_{2}$, which both will be validated.

Subsequently, validation focus will be put in our study on precision and dynamic response of the SCIAMACHY retrievals. I.e., we will investigate, whether the atmospheric day-to-day variabilities, which are dominated by dynamically induced tropopause movements, can be retrieved from the SCIAMACHY data. Furthermore, we find from the Zugspitze FTIR measurements, that the amplitude of the sinusoidal $\mathrm{XCH}_{4}$ annual cycle (dominated by the tropopause annual cycle) is only slightly larger than the standard deviation of the day-to-day scatter (see Sect. 4). Therefore, it is challenging to investigate the potential of the SCIAMACHY retrievals to reflect the dynamic response to this weak annual cycle in spite of limited precision and time dependent biases due to the detector-icing issue.

Our approach to this is as follows. Individual WFMD retrievals in the near-infrared spectral domain are showing a significant scatter. The reasons are discussed in detail by Buchwitz and Burrows (2004) and Buchwitz et al. (2005a). Therefore, our validation approach is investigating to what extent the quality of SCIAMACHY data allows to approach the true variability of $\mathrm{CH}_{4}$ columns as a function of the amount of the averaging of individual measurements performed in time and space. For this purpose, we are using daily-mean pixel averages within a stepwise increased selection radius around the Zugspitze ground site. The goal is to thereby stepwise reduce the scatter of the daily means by statistically averaging over increasing ensembles of pixels. 
One might argue that also source and sink regions may be more and more included into the ensemble while increasing the selection radius, and this could potentially be compensating the statistical effect of reducing the scatter of the daily means. However, this effect is obviously weaker than the reduction of scatter by the statistical effect of increasing the averaging ensemble, as our test of the statistical parameters in Sect. 4 (Table 1) below is proving.

Since we are using selection radii of up to $2000 \mathrm{~km}$ around the Zugspitze, i.e., daily averages of $\mathrm{XCH}_{4}$ values from all the SCIAMACHY pixels available within this radius for that day, the question arises how i) the absolute $\mathrm{XCH}_{4}$ values, ii) the amplitude of their annual cycle, and iii) the day-today variability of the $2000-\mathrm{km}$ averages compare to the corresponding quantities seen in the column time series above the center site (i.e., the Zugspitze). Ad i) we state that we expect no significant bias (i.e., less than a few percent) between the daily average column averaged mixing ratio above a single site (e.g., $47^{\circ} \mathrm{N}, 11^{\circ} \mathrm{E}$ ), and an average over a 2000 $\mathrm{km}$ radius around that site on that day. The argumentation for this is as follows. First of all, we obtained a standard deviation of the individual SCIAMACHY column averaged mixing ratios of $\approx 5.2 \%$ using all pixels per day within the 2000-km selection radius (Sect. 4.2.3, Table 1). Using this value we derive an estimate of the standard deviation of the true individual $\mathrm{XCH}_{4}$ values within the $2000-\mathrm{km}$ radius of $\approx 4 \%$ per day. This is obtained assuming a quadratic error superposition of the true scatter together with the known statistical SCIAMACHY error sources, i.e., instrumental noise causing an $\approx 1 \%$ error (Buchwitz et al., 2005a) as well the so called-retrieval noise of $\approx 3 \%$ (the latter resulted from a comparison to models in Buchwitz et al., 2005b). We state that this variability of $\approx 4 \%$ within the $2000-\mathrm{km}$ selection circle is dominated by regional sources and sinks, and this scattering effect appears strongly reduced by a factor in the order of $\approx 10$, considering the "standard deviation of the mean value" of all radius-2000-km values, as done in Sect. 4.2.3 below (Table 1). From these considerations it is obvious, that we do not expect any significant bias between the column averaged mixing ratio obtained at the Zugspitze site (which shows a day-to-day variability of only $\approx 1 \%$ and is located in the free troposphere and is therefore representative for a wider horizontal area), versus that obtained from the $2000-\mathrm{km}$ radius average. In particular, it becomes clear that the current study focusing upon characterization of a time-dependent bias of SCIAMACHY in the order of $\approx 10 \%$, is not significantly affected by any possible bias due to the horizontal averaging. As an additional effect, the well known north-south gradient in the tropopause altitude results in an absolute tropopause increase of $\approx 2 \mathrm{~km}$ between the northern boarder and the southern boarder of our selection circle. However, this transfers only to a gradient of $\mathrm{XCH}_{4}$ of $\approx 2 \%$ expected between the northern and southern boarder. The underlying relation for the change of $\mathrm{XCH}_{4}$ with the tropopause altitude was derived using an ensemble of radio-sonde pressure-temperature profiles with differing tropopause altitudes, together with a methane volume mixing ratio profile that was iteratively distorted according to varying tropopause altitudes (vertical scale linearly compressed or stretched below and above the tropopause, respectively, or vice versa). I.e., there is a small north-south increase of the columns within our selection radius on the $\approx 2 \%$ level, but since it is to a good approximation a linear increase, this does not introduce any significant bias to the $2000-\mathrm{km}$ average versus the center-site value, considering the magnitude of the effect we are investigating in this study, i.e., the $\approx 10 \%$ time-dependent bias effects. Ad ii) we expect the amplitude of the annual cycle in the 2000$\mathrm{km}$ radius daily averages to be very close to the magnitude of the amplitude at the center (Zugspitze) site. For an explanation, we make reference to the FTIR station at Izaña (Teneriffa, $28^{\circ} \mathrm{N},-16^{\circ} \mathrm{E}$ ) which shows an amplitude of the annual cycle of $\approx 1 \%$ (I. Kramer, personal communication, 2005), which is within the same order of magnitude as the Zugspitze amplitude of $\approx 1.6 \%$ (see Sect. 4.2.1), and shows the same phase. Since the annual cycles both at the center site (Zugspitze) and at the southern boarder site (Izaña) are in the same order of $\approx 1-2 \%$, and they are showing the same phase, we conclude, that the amplitude of the annual cycle of the full $2000-\mathrm{km} \mathrm{XCH}_{4}$ average is also within this same order of $\approx 1-2 \%$, i.e., it is by no means expected to be completely different in amplitude or phase. Ad iii) we state that the dayto-day variability of the $2000-\mathrm{km}$ radius average is probably in the same order of magnitude as that above the center (Zugspitze) site $(\approx 1 \%)$, with a tendency to be smaller. We derive this from the consideration that day-to-day variabilities of column averaged methane are caused by tropopause movements due to synoptic planetary-wave activity, and this effect might be somewhat reduced due to averaging, when using the $2000-\mathrm{km}$ radius mean $\mathrm{XCH}_{4}$ values, compared to when using individual-site values.

Another issue of the validation approach is how to reduce the impact of varying ground altitudes of the different satellite pixels that are averaged on one hand, and the (higher) altitude of the Zugspitze mountain site on the other hand. We solve this problem by focusing our validation study on $\mathrm{XCH}_{4}$ data, i.e., the column averaged mixing ratios. This quantity does not depend on the average pixel ground-level altitude, assuming a constant mixing ratio with altitude. This approximation does not introduce significant additional errors, as measured $\mathrm{CH}_{4}$ profiles are typically showing nearly constant volume mixing ratios as a function of altitude up to the tropopause. Deviations from this behavior are in the few per cent range, with a tendency to approach perfectly constant mixing rations as a function of altitude after averaging of only a few profiles.

Related to this issue, one might argue whether a highaltitude mountain site or a low-altitude ground site, located in the boundary layer, is to be preferred for satellite validation of tropospheric species like $\mathrm{CH}_{4}$. On the one hand, as discussed above, for a high-altitude site the altitude difference 
relative to the satellite-pixel ground altitude has to be properly considered, which may introduce errors on the percent level. On the other hand, a high-altitude site like the Zugspitze located above the boundary layer has the advantage to be representative for a much wider horizontal area, and that is exactly what the satellite data are - we will show below that not only the pixel size of the satellite data $(60 \times 30 \mathrm{~km}$ footprint $)$, but even larger horizontal averages, e.g., selection radii in the order of $1000 \mathrm{~km}$, have to be considered for the validation purposes.

Finally, an important issue in intercomparing two different remote-sounding systems (satellite versus ground) is to properly take their altitude-dependent sensitivities, i.e., their averaging kernels (Rodgers, 1990) into account. In case of strongly differing kernels, neglecting the effect of different smoothing errors can result in intercomparison errors in the order of the natural variability of the trace-gas columns (Rodgers and Connor, 2003). However, in our case we encounter the nearly ideal situation, that the groundbased (FTIR) and satellite (SCIAMACHY) instruments are both sampling the $\mathrm{CH}_{4}$ columns with nearly the same totalcolumn averaging kernels as shown in Fig. 1, i.e., both being close to the ideal uniform sampling. The FTIR kernel shown is a weighted mean of the two (slightly differing) FTIR kernels we obtain from utilizing the two different spectral microwindows from alternating MCT and InSb measurements as described in Sect. 2. This mean was weighted by the number ratio of all spectra of the two different spectral domains used in our study (i.e., 859/781, see Sect. 2). The resulting effective FTIR kernel shows only minor differences relative to the SCIAMACHY-WFMD kernel, e.g., at the $700 \mathrm{hPa}$ level, there is a slight under-estimation of the natural variability of $\approx 13 \%$ by FTIR, and a slight overestimation of $\approx 14 \%$ by SCIAMACHY (Fig. 1). In the stratosphere the situation is reversed, with the underestimations/overestimations increasing with altitude. However, due to the decreasing air-number density the latter does not quantitatively impact the total columns retrieved. To prove this quantitatively, we calculated the smoothing errors $\operatorname{sqrt}\left[\left(\boldsymbol{a}_{\mathrm{FTIR}}-\boldsymbol{a}_{\text {ideal }}\right)^{T} \mathbf{S}_{\mathbf{a}}\left(\boldsymbol{a}_{\mathrm{FTIR}}-\boldsymbol{a}_{\text {ideal }}\right)\right]$ for the total columns using the kernels (vectors $\boldsymbol{a}_{\text {FTIR }}$ and $\left.\boldsymbol{a}_{\text {WFMD }}\right)$ shown in Fig. 1, and the total-column kernel $\boldsymbol{a}_{\text {ideal }}$ of an ideal remote-sounding system with $\boldsymbol{a}_{\text {ideal }}^{T}=(111 \ldots 1)$. For $\mathbf{S}_{\mathbf{a}}$ we adapted a best-estimate variance-covariance matrix of the atmospheric $\mathrm{CH}_{4}$ variabilities. The relative vertical change of the diagonal elements (variances) were adopted from results of the Karlsruhe Simulation Model of the Middle Atmosphere (KASIMA). The absolute values of the variances were then scaled in order to reflect the total-column day-to-day variability found by our FTIR measurements (this procedure will be detailed with numbers in Sect. 4 below). For the off-diagonals (covariances) a Gaussian-shaped interlayer correlation with length of $2.5 \mathrm{~km}$ was used. Thereby we end up with smoothing errors of $0.10 \%$ for FTIR and $0.14 \%$ for SCIAMACHY WFMD, respectively. These errors are small relative to the bias found between FTIR and SCI-

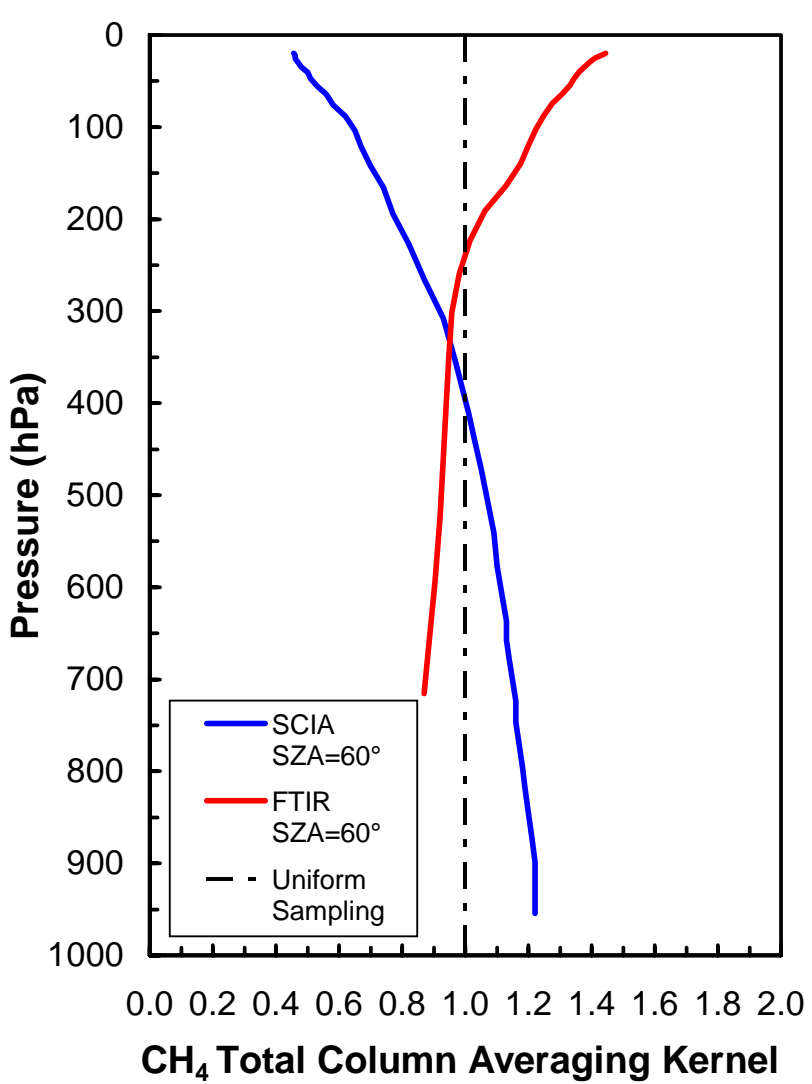

Fig. 1. Total-column averaging kernels for Zugspitze FTIR (red line) and SCIAMACHY-WFMD $\mathrm{CH}_{4}$ retrievals (blue line) calculated for a solar zenith angle (SZA) of $60^{\circ}$.

MACHY WFMD, and relative to the differences in day-today scatter encountered for FTIR and WFMD, respectively during our intercomparisons of Sect. 4. For consistency reasons, we briefly state that we do not distinguish between smoothing errors of $\mathrm{CH}_{4}$ columns and $\mathrm{XCH}_{4}$, respectively, i.e., we are neglecting the smoothing error contribution from the $\mathrm{CO}_{2}$ retrieval (being part of the WFMD $\mathrm{XCH}_{4}$ retrieval) throughout this paper. This simplification is valid because the natural variability of column averaged $\mathrm{CO}_{2}$ is known to be significantly ( $\approx$ factor 4 ) smaller than for $\mathrm{CH}_{4}$ (Buchwitz et al., 2005a). All in all, our validation results are not impacted significantly by smoothing errors. In Sects. 4.1.2 and 4.2.2 we will add absolute numbers as to this (small) smoothingerror effect on the bias and relative day-to-day scatter we obtained during our intercomparison study.

It is noteworthy, that the SCIAMACHY retrievals (and also the ground-based measurements) are perfectly sensitive down to the lower troposphere. This is indicated by the kernels in Fig. 1 showing numbers significantly above zero. This is due to the near-infrared spectral domain utilized for the SCIAMACHY retrievals, and is advantageous over thermalIR satellite retrievals which are showing a reduced sensitivity in the boundary layer. 


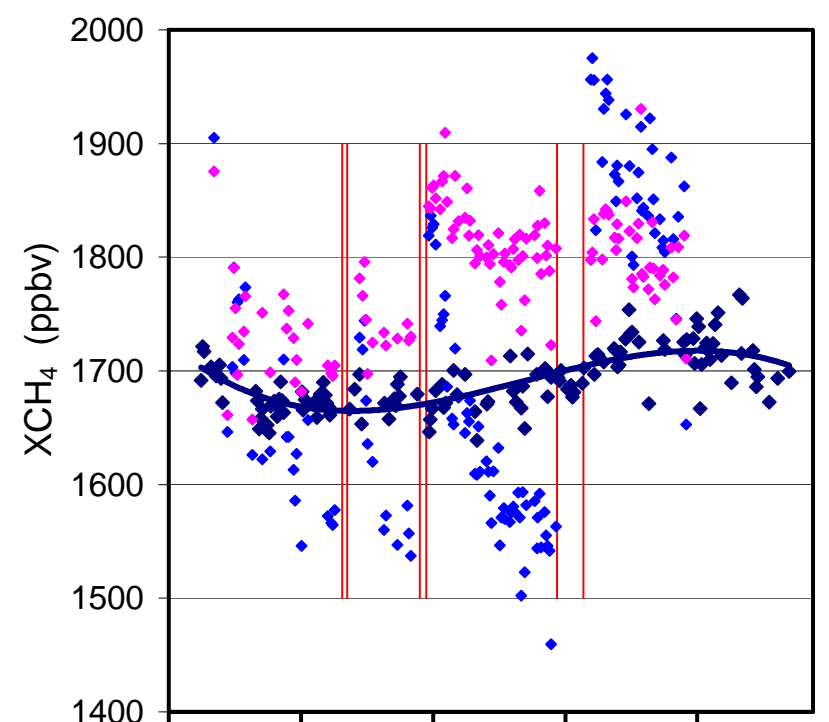

Dec-02 Mar-03 May-03 Aug-03 Nov-03 Date

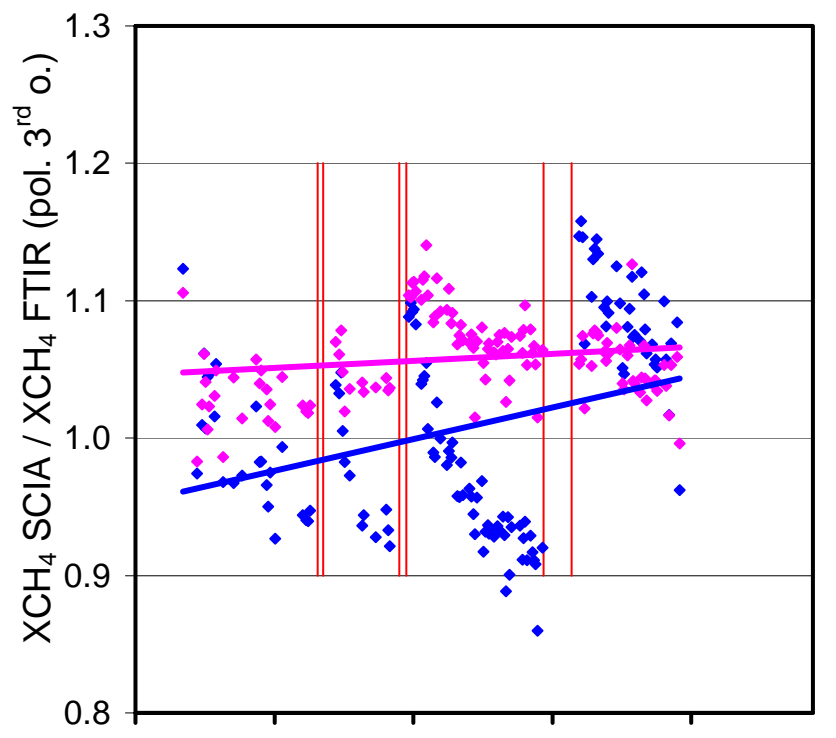

Dec-02 Mar-03 May-03 Aug-03 Nov-03

Date

(b)

Fig. 2. (a) $\mathrm{XCH}_{4}$ daily-mean values plotted for FTIR (dark blue, incl. 3rd order polynomial fit) and averages of all SCIAMACHY WFMD data for a 2000-km selection radius around Zugspitze for each day; v0.4 (azur) and v0.41 (pink). (b) SCIAMACHY XCH $\mathrm{X}_{4}$ data (azur: v0.4, pink: v0.41) divided by the 3rd order polynomial fitted to the FTIR data taken from (a). SCIAMACHY decontamination phases are indicated by red vertical lines.

\section{Validation results}

\subsection{Overall bias}

\subsubsection{Correlative study FTIR versus WFMD: bias}

Figure 2a shows all SCIAMACHY WFMD $\mathrm{XCH}_{4}$ data currently available (i.e., versions 0.4 and 0.41 ). Each SCIAMACHY data point is the average of all pixels from one day within a $2000-\mathrm{km}$ radius around the Zugspitze. Cloud flagged pixels have been removed, and we restricted the WFMD data to a maximum threshold of $10 \%$ in the individual retrieval errors reported. Additionally, a flag for erroneous retrievals had been added with the version 0.41 release, and, subsequently, we excluded all error-flagged data for both versions (i.e., 0.4 and 0.41 ) for this study. Zugspitze FTIR daily-mean $\mathrm{XCH}_{4}$ data are shown in the same plot. A 3rd order polynomial fit to the FTIR data nicely shows the $\mathrm{XCH}_{4}$ annual cycle with a $\approx 1.6 \%$ amplitude.

In order to obtain the bias of the SCIAMACHY WFMD data relative to the FTIR data we normalized the SCIAMACHY data by the 3rd order polynomial fit to the FTIR data. The result is shown in Fig. 2b. Note, that we do not investigate pairwise "coincidences", as performed in many validation studies. Rather, we herewith propose the approach of fitting a polynomial to the reference series (FTIR) that is subsequently used as a reference. This ap- proach allows to compare time series even in case of alternating time-gaps, which would not allow for the use of "coincidences". This is partially the case for our time series of SCIAMACHY (measurement gaps due to decontamination phases) and FTIR (measurement gaps due to the clear-sky requirement). From Fig. $2 \mathrm{~b}$ we retrieve an overall $\mathrm{XCH}_{4}$ bias for WFMD v0.4/FTIR $=1.008 \pm 0.019$ and WFMD $\mathrm{v} 0.41 / \mathrm{FTIR}=1.058 \pm 0.008$. The statistical errors of the biases given are $3 \times$ standard deviation/sqrt $(n)$, where $n=126$ is the number of the WFMD data points.

\subsubsection{Estimate of intercomparison error: impact on bias}

We briefly want to estimate, whether the bias of $5.8 \%$ found for WFMD v0.41 can be partially affected by the slightly differing averaging kernels, and the different a priori profiles used for FTIR and WFMD, respectively. Therefore, we calculated the term $\boldsymbol{a}_{\mathrm{FTIR}}^{T}\left(\boldsymbol{x}_{a \mathrm{FTIR}}-\boldsymbol{x}_{a \mathrm{WFMD}}\right) /$ total col$\mathrm{umn}=0.74 \%$ and the analogous term, i.e., $\boldsymbol{a}_{\mathrm{WFMD}}^{T}\left(\boldsymbol{x}_{a \mathrm{WFMD}^{-}}\right.$ $\left.\boldsymbol{x}_{a \mathrm{FTIR}}\right) /$ total column $=0.93 \%$, where $\boldsymbol{a}$ are the total-column averaging kernel vectors and $\boldsymbol{x}_{a}$ are the vectors of the a priori profiles. The numbers obtained indicate that the effect from slightly differing a priori profiles and averaging kernels is only a minor contribution to the observed bias of WFMD $\mathrm{v} 0.41$. 


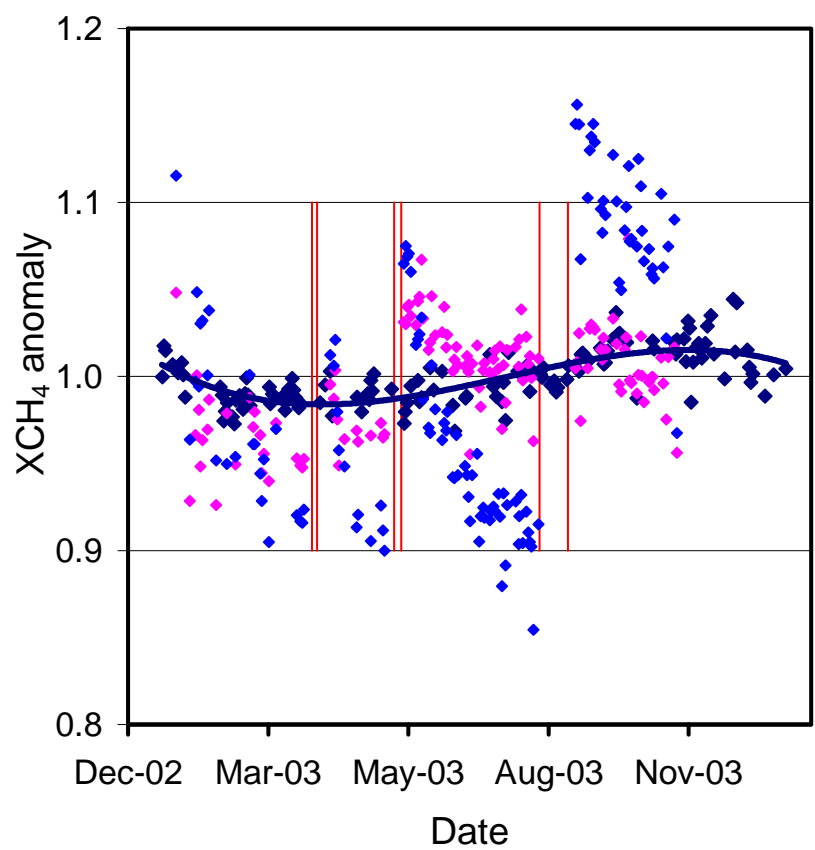

Fig. 3. Dark blue points: Anomaly of Zugspitze FTIR $\mathrm{XCH}_{4}$ daily means. Dark blue line: 3rd order polynomial fit to FTIR data. Azur points: Anomaly of SCIAMACHY WFMD v0.4 $\mathrm{XCH}_{4}$; average of all data within a 2000-km radius around Zugspitze for each day. Pink points: Same as azur points but for SCIAMACHY WFMD v0.41. SCIAMACHY decontamination phases are indicated by red vertical lines.

\subsection{Time-dependent bias, precision, and variability}

\subsubsection{Precision and variability of the FTIR column data set}

Figure 3 shows the FTIR data set (together with WFMD v0.4, WFMD v0.41), but now plotted as anomaly, i.e., the daily mean data are normalized with respect to their overall average. First, is obvious that the FTIR data are monitoring a sinusoidal annual cycle with a $\approx 1.6 \%$ amplitude. The dominant cause for this is the corresponding annual cycle of the tropopause altitude. Second, it is obvious that the FTIR daily-mean data are showing some scatter of $\approx 1 \%$ around this sinusoidal cycle. We will show below that this variability is not caused by limited precision of the FTIR measurements but is dominated by the true atmospheric day-to-day variability caused by the dynamic effect of planetary-wave activity.

In the following we want to investigate statistical parameters describing the scatter of the FTIR data in detail. Table 1 gives in the first 3 columns the statistical numbers describing the "individual" (FTIR) measurements within one measurement day. On average over the ensemble of $i=133$ FTIR measurement days, 12.3 FTIR column measurements have been performed per day. As a measure for the precision of individual FTIR measurements, the overall average of the standard deviations $\sigma_{i}$ of the individual measurements of each

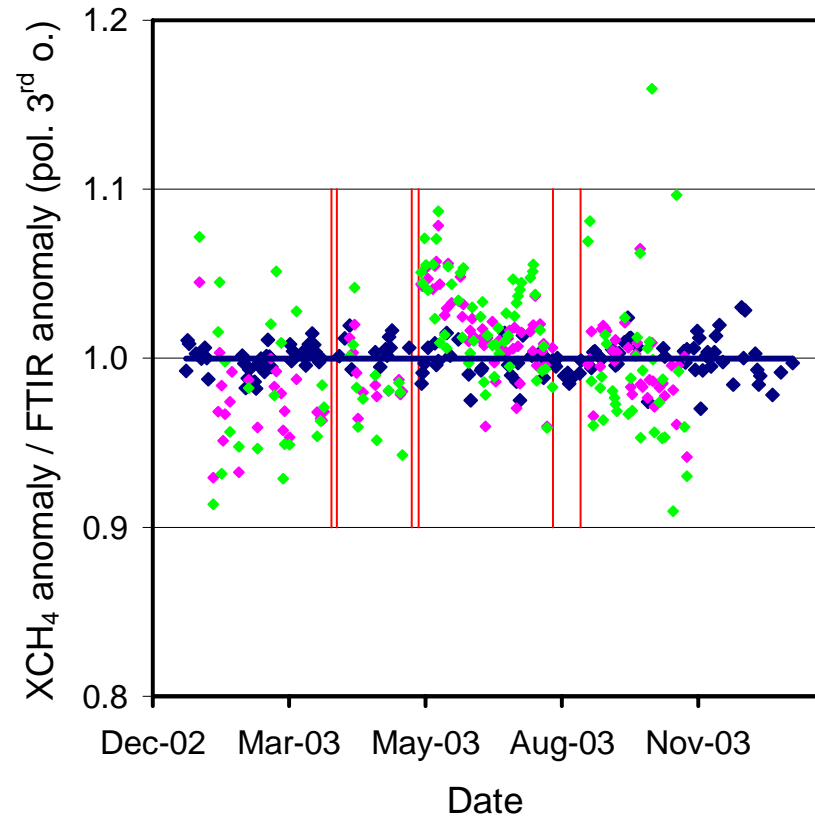

Fig. 4. Dark blue points: Zugspitze FTIR $\mathrm{XCH}_{4}$ anomaly daily means normalized to the annual cycle (i.e., the 3 rd order polynomial of Fig. 3). Pink points: SCIAMACHY WFMD v0.41 $\mathrm{XCH}_{4}$ anomaly; average of all pixels within a $2000-\mathrm{km}$ radius around Zugspitze for each day normalized to the annual cycle (i.e., the 3rd order polynomial of Fig. 3). Green points: Same as pink points but for a $1000-\mathrm{km}$ selection radius around Zugspitze. SCIAMACHY decontamination phases are indicated by red vertical lines.

day is given in Table 1, i.e., $\operatorname{AV}_{i}\left(\sigma_{i}\right)=1.3 \%$ for FTIR. Furthermore, as a measure for the statistical error for one FTIR daily-mean value, the overall average for the daily "standard deviations of the mean value", i.e., $\operatorname{AV}_{i}\left(\sigma_{i} / \operatorname{sqrt}\left(n_{i}\right)\right)$ calculated from the individual measurements is given in Table 1. $\operatorname{AV}_{i}\left(\sigma_{i} / \operatorname{sqrt}\left(n_{i}\right)\right)$ equals $0.4 \%$ for FTIR.

Now we discuss the standard deviations calculated from the FTIR "daily-mean" data. Of course, prior to this calculation from the daily means, the FTIR time series has to be normalized with respect to its obvious annual cycle. See, e.g., Fig. 4 for the result of this normalization. Table 1 shows in column 4 that the resulting standard deviation for FTIR is $1 \%$.

Finally, we want to discuss the obvious discrepancy between the standard deviations we calculated from the daily mean data (1\% for FTIR, see Table 1), and the average statistical error of the daily means calculated from the individual measurements, which is $\operatorname{AV}_{i}\left(\sigma_{i} / \operatorname{sqrt}\left(n_{i}\right)\right)=0.4 \%$ for FTIR. Clearly the numbers indicate, that the standard deviation of $1 \%$ obtained from the FTIR daily means is dominated by true atmospheric day-to-day-variability due to tropopause movements, and not by the statistical error (due to limited single-measurement precision) which is only $\mathrm{AV}_{i}\left(\sigma_{i} / \operatorname{sqrt}\left(n_{i}\right)\right)=0.4 \%$. 
4.2.2 Estimate of intercomparison error: impact on variability

Here we like to address the question, to which degree possible differences in the day-to-day variability observed by the FTIR and WFMD, respectively might be attributed to smoothing errors. In the following we present a simple but quantitative estimate for FTIR and WFMD retrievals.

We write the variance of daily-mean total columns $\operatorname{col}_{\mathrm{FTIR}}$ observed by FTIR as $\sigma^{2}\left(\operatorname{col}_{\mathrm{FTIR}}\right)=\boldsymbol{a}_{\mathrm{FTIR}}^{T} \mathbf{S}_{\mathbf{a}} \boldsymbol{a}_{\mathrm{FTIR}}+$ $\sigma^{2}\left(\varepsilon_{\mathrm{FTIR}}\right)$, where vector $\boldsymbol{a}_{\mathrm{FTIR}}$ is the total-column averaging kernel, and $\mathbf{S}_{\mathbf{a}}$ is the a priori variance-covariance matrix described in Sect. 3 above. The term $\boldsymbol{a}_{\mathrm{FTIR}}^{T} \mathbf{S}_{\mathbf{a}} \boldsymbol{a}_{\mathrm{FTIR}}$ describes the variance due to the true variability of the atmosphere, smoothed by the measurement. By the second term $\sigma^{2}\left(\varepsilon_{\text {FTIR }}\right)$, we denote all further contributions which do not originate from the true variability of the atmosphere, i.e., contributions due to any kind of random-type measurement errors. Using $\sigma\left(\operatorname{col}_{\mathrm{FTIR}}\right)=1 \%$ from Table 1, and using for the error term $\sigma\left(\varepsilon_{\mathrm{FTIR}}\right)=\mathrm{AV}_{i}\left(\sigma_{i} / \operatorname{sqrt}\left(n_{i}\right)\right)=0.4 \%$ (see Table 1), we find that it should hold $\operatorname{sqrt}\left(\boldsymbol{a}_{\mathrm{FTIR}}^{T} \mathrm{~S}_{\mathrm{a}} \boldsymbol{a}_{\mathrm{FTIR}}\right) /$ total column $=0.92 \%$. We now use $\boldsymbol{a}_{\text {FTIR }}$ of Fig. 1 and scale $\mathbf{S}_{\mathbf{a}}$ to fulfil this relation. (See Sect. 3 for the adopted principle shape of $\mathbf{S}_{\mathbf{a}}$.) Using the resulting best-estimate $\mathbf{S}_{\mathbf{a}}$ we calculate for WFMD analogously $\operatorname{sqrt}\left(\boldsymbol{a}_{\mathrm{WFMD}}^{T} \mathbf{S}_{\mathrm{a}} \boldsymbol{a}_{\mathrm{WFMD}}\right) /$ total column $=0.93 \%$. For an ideal observing system with $\boldsymbol{a}_{\text {ideal }}^{T}=(111 \ldots 1)$ we would obtain $\operatorname{sqrt}\left(\boldsymbol{a}_{\text {ideal }}^{T} \mathbf{S}_{\mathbf{a}} \boldsymbol{a}_{\text {ideal }}\right) /$ total column $=0.94 \%$. These numbers tell us that FTIR is underestimating the true variability by a factor of $0.92 / 0.94=0.98$ and WFMD by a factor of $0.93 / 0.94=0.99$ due to the smoothing effect. These underestimations are both similar to each other, and small in absolute terms. This means that possible differences in the day-to-day variability observed by the FTIR and WFMD, respectively (as discussed in the next Section) do not contain significant contributions from smoothing errors.

4.2.3 Correlative study FTIR versus WFMD: Timedependent bias, precision, and variability

Figure $2 \mathrm{~b}$ shows that the time-dependent bias correction introduced with version 0.41 for $\mathrm{XCH}_{4} \mathrm{WFMD}$, in order to account for the icing issue, did result in a significant reduction in the time dependence of the bias relative to version 0.4. This holds for both the time dependencies on the monthly scale, i.e., in between the various decontamination phases (marked by red vertical lines in Fig. 2b), as well as for the overall time dependence of the bias on the annual scale, as indicated by the linear fits in Fig. $2 b$.

Figure 3 again shows the three data sets (FTIR, WFMD v0.4, WFMD v0.41) but now plotted as anomalies, i.e., each data set is normalized with respect to its overall average. This shows even more obvious than Fig. 2a, that the changes associated with the version 0.41 update succeeded in significantly reducing the time-dependent bias compared to version 0.4 .
However, Fig. 3 also shows, that there is still a residual time dependence also in the version 0.41 data, which is clearly related to the decontamination cycles.

Figure 4 shows the WFMD v0.41 daily data both averaged for a selection radius of $1000 \mathrm{~km}$ around Zugspitze, as well as for a $2000-\mathrm{km}$ radius. Note, that in Fig. 4 all three data sets have additionally been normalized to the annual cycle, i.e., the 3 rd order polynomial fit to the FTIR data shown in Fig. 3. Figure 4 shows that the scatter of the daily WFMD data clearly exceeds the scatter of the FTIR daily means. It can also be seen that the WFMD data for a 1000-km selection radius are showing a higher scatter compared to the WFMD data for a $2000-\mathrm{km}$ selection radius, as expected.

The question arises whether the scatter of the WFMD data in Fig. 4 is limited by systematic issues like a residual time-dependent bias due to the icing issue, or by the limited precision of the individual column retrievals, i.e., the limited signal-to-noise ratio of the SCIAMACHY spectra. This is further investigated in Fig. 5a. We restrict here to SCIAMACHY data out of one uninterrupted measurement period between two decontamination phases, i.e., the period 25 May-12 August 2003. We haven chosen this time period, because here a systematic time dependence of WFMDselection-radius-2000-km data can be most clearly identified, see Fig. 5a. Figure 5a shows a polynomial (2nd order) fit to this time dependence of the WFMD-selection-radius-2000$\mathrm{km}$ data, which reflects a residual time-dependent bias of $\approx 3 \% /$ month. In Fig. $5 \mathrm{~b}$ the WFMD data (both for $1000-\mathrm{km}$ and $2000-\mathrm{km}$ selection radii) are empirically normalized to this time dependence.

Having eliminated all residual systematic time dependence on an empirical best-effort basis (Fig. 5b), the next step is to investigate the statistical parameters describing the scatter of the WFMD version 0.41 data in comparison to the scatter of FTIR data in full detail. First, Table 1 gives the statistical numbers describing the "individual" measurements for FTIR and WFMD v0.41. While the number of days for which FTIR data exist (133) is comparable to the number of data for which WFMD data exist, Table 1 shows that average $\operatorname{AV}_{i}\left(n_{i}\right)$ of the number $n_{i}$ of daily measurements are quite different, i.e., 12.3 FTIR measurements per day on average versus 249 and 85 individual WFMD measurements per day for a $2000-\mathrm{km}$ and a $1000-\mathrm{km}$ selection radius, respectively. As a measure for the precision of the individual measurements $\operatorname{AV}_{i}\left(\sigma_{i}\right)$, i.e., the overall average of the standard deviations of the individual measurements of each day is given in Table 1 . The precisions are quite different, i.e., $\operatorname{AV}_{i}\left(\sigma_{i}\right)=1.3 \%$ for FTIR, and a factor of 4 lower precisions are encountered for $\mathrm{WFMD}$, i.e., $\mathrm{AV}_{i}\left(\sigma_{i}\right)$ equals $5.2 \%$ and $5.4 \%$ for calculation of $\mathrm{AV}_{i}\left(\sigma_{i}\right)$ from the $2000-\mathrm{km}$ and $1000-\mathrm{km}$ selection ensembles, respectively. Note, that the WFMD single-measurement standard deviations are nearly identical (5.2 versus $5.4 \%$ ), i.e., nearly independent on the size of the selected ensemble (1000-km versus $2000-\mathrm{km}$ selection radius), as expected for an ideal random ensemble. 


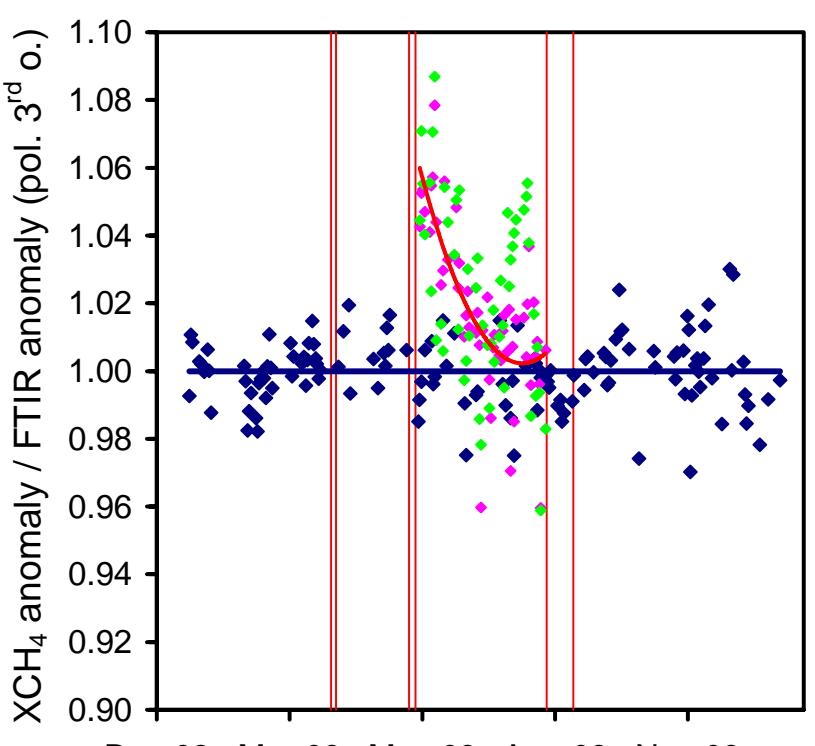

Dec-02 Mar-03 May-03 Aug-03 Nov-03

Date

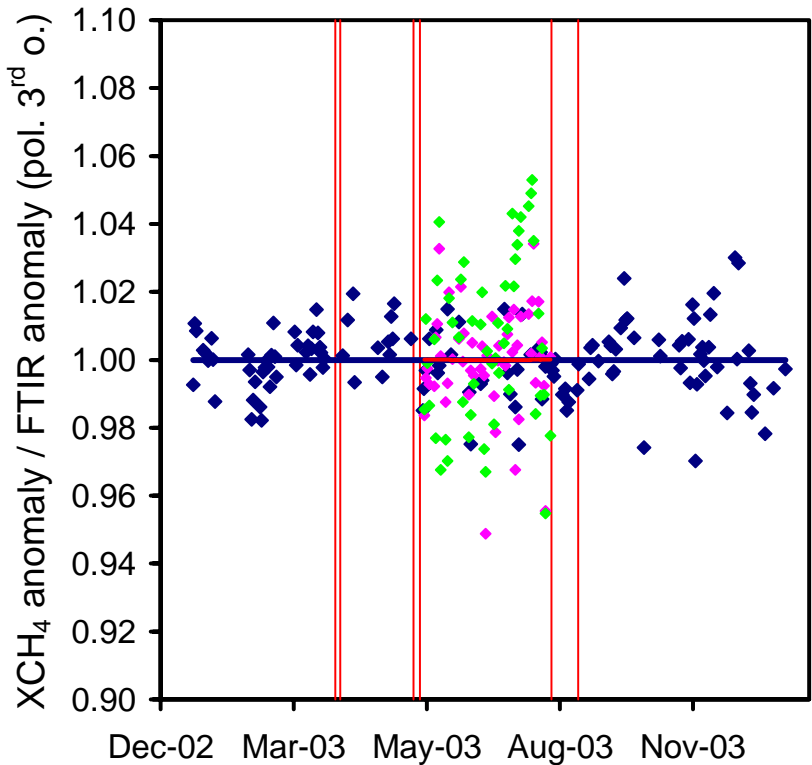

(a)
Date

Fig. 5. (a) Same as Fig. 4 but SCIAMACHY data restricted to 25 May-12 August 2003 and a polynomial fit performed to the SCIAMACHY data with selection radius $2000 \mathrm{~km}$. (b) Same as (a) but data normalized to the polynomial of (a). SCIAMACHY decontamination phases are indicated by red vertical lines.

Furthermore, as a measure for the statistical error for one daily mean value, the overall average for the daily "standard deviations of the mean value", i.e., $\operatorname{AV}_{i}\left(\sigma_{i} / \operatorname{sqrt}\left(n_{i}\right)\right)$ calculated from the individual measurements is given in Table 1 . $\mathrm{AV}_{i}\left(\sigma_{i} / \operatorname{sqrt}\left(n_{i}\right)\right)$ equals $0.4 \%$ for FTIR, and for WFMD $0.6 \%$ and $0.3 \%$ for the $1000-\mathrm{km}$ and the $2000-\mathrm{km}$ selection radii, respectively. Note again, that this factor-of-two reduction of $\mathrm{AV}_{i}\left(\sigma_{i} / \operatorname{sqrt}\left(n_{i}\right)\right)$ on doubling the selection radius nicely reflects what we would expect for an ideal statistical ensemble. This confirms our assumption of Sect. 3, that the possible effect that also source and sink regions may be more and more included into the ensemble while increasing the selection radius might potentially compensate for the intended reduction of the standard deviation of the daily mean value (by increasing the selection radius), is quantitatively negligible. All in all we have found with a selection radius somewhere between $1000-2000 \mathrm{~km}$ the threshold, where the statistical errors of WFMD-daily-mean data become comparable to the ones of the FTIR, i.e. in the order of $0.5 \%$. Note, that we had obtained a related result validating the species $\mathrm{CO}$ in our recent work (Sussmann and Buchwitz, 2005).

Now we discuss the standard deviations calculated from the daily mean data. Table 1 shows in column 5 and 6 the results with and without our empirical correction for a residual systematic time dependence (see Figs. 5a and b). As an important result, it can be seen from Table 1, that in fact the scatter of the WFMD-selection-radius-2000-km-data had been limited by a residual systematic time dependence. This results from the finding that the standard deviation of daily means could be reduced from $2.4 \%$ to $1.6 \%$ by our simple and merely illustrative empirical time-dependent bias correction of Fig. 5b. Note, that this is now close to the day-to-day variability of $\approx 1 \%$ observed at the Zugspitze site. However, as stated earlier, an even smaller true day-to-day variability is expected for a $2000-\mathrm{km}$ mean value due to the averaging effect (Sect. 3). I.e., there appears to be still some potential for further improvements.

Finally, we want to discuss the obvious discrepancy between the standard deviations we calculated from the daily-mean data (1\% for FTIR and $1.6 \%$ for 2000km-WFMD after correcting for annual cycle and timedependent bias, see Table 1), and the average statistical errors of the daily means calculated from the individual measurements, which is $\operatorname{AV}_{i}\left(\sigma_{i} / \operatorname{sqrt}\left(n_{i}\right)\right)=0.4 \%$ for FTIR, and $\mathrm{AV}_{i}\left(\sigma_{i} / \operatorname{sqrt}\left(n_{i}\right)\right)=0.3 \%$ for 2000-kmWFMD, and $\operatorname{AV}_{i}\left(\sigma_{i} / \operatorname{sqrt}\left(n_{i}\right)\right)=0.6 \%$ for $1000-\mathrm{kmWFMD}$, see Table 1 . Interpretation is easy for FTIR, where no time-dependent drift is expected. Here clearly the numbers indicate that the standard deviation of $1 \%$ obtained from the FTIR daily means is dominated by true atmospheric day-to-day-variability due to tropopause movements, and not by the statistical error (due to limited single-measurement precision) which is only $\mathrm{AV}_{i}\left(\sigma_{i} / \operatorname{sqrt}\left(n_{i}\right)\right)=0.4 \%$. Interpretation for the satellite data is not so straight forward. Here, we have to stress that the statistical error for a daily mean value, i.e., $\operatorname{AV}_{i}\left(\sigma_{i} / \operatorname{sqrt}\left(n_{i}\right)\right)$ is calculated from the individual measurement data obtained 
during the individual measurement days, i.e., it can in principle not describe time-dependent drifts on the weekly or monthly scale. Therefore the conclusion from our statistical numbers given above can only be, that WFMD data have the potential - as to their precision - to retrieve natural variabilities down to the $0.3 \%$ level for a $2000 \mathrm{~km}$-selection radius and down to the $0.6 \%$ level for a $1000-\mathrm{km}$ selection radius "if" all systematic type time-dependent drifts would/could be eliminated.

\section{Conclusions}

Solar FTIR measurements at the Permanent GroundTruthing Station Zugspitze $\left(47.42^{\circ} \mathrm{N}, \quad 10.98^{\circ} \mathrm{E}\right.$, $2964 \mathrm{~m}$ a.s.1.), Germany were used to validate the ENVISAT/SCIAMACHY Scientific Data Product for $\mathrm{XCH}_{4}$ retrieved at the University of Bremen, i.e., the near infrared WFM-DOAS version 0.4 and 0.41 products.

The averaging kernels of the ground-based FTIR technique turned out to be similar shaped as the SCIAMACHY WFMD kernels, which both maintain a nearly uniform sampling down to the lower troposphere. Therefore, both a direct comparison of absolute column levels (bias) and the intercomparison of the day-to day-scatter is possible without introducing significant intercomparison errors from smoothing errors, which have been estimated to be below $0.10 \%$ for FTIR and $0.14 \%$ for SCIAMACHY WFMD retrievals, respectively.

In order to account for the altitude difference between the ground altitudes of the satellite pixels and the Zugspitze, $\mathrm{XCH}_{4}$ columns have been used for both the satellite and ground-based data sets for the intercomparison. This approach eliminates the effect of the altitude difference for the case of a constant volume mixing ratio throughout the altitude range to be accounted for. This assumption should hold for the case of the lower tropospheric $\mathrm{CH}_{4}$ profile within the per cent level.

Analysing the 2003-time series of the Zugspitze FTIR, we characterized the natural variability of $\mathrm{XCH}_{4}$. It displays a $1 \%$ day-to-day variability and a sinusoidal annual cycle with a $\approx 1.6 \%$ amplitude which is both dominated by related tropopause movements.

In order to obtain the bias of the SCIAMACHY WFMD data relative to the FTIR data we used a new approach, i.e., we did not investigate pairwise "coincidences" (satellite versus ground), which are limited in number in case of data series with time-gaps (e.g., decontamination phases, clear sky restrictions). Therefore, we fitted a polynomial to the reference series (FTIR) that is subsequently used as a reference. We obtained an overall $\mathrm{XCH}_{4}$ bias for WFMD v0.4/FTIR $=1.008 \pm 0.019$ and WFMD v0.41/FTIR $=1.058 \pm 0.008$.

Finally, we investigated whether WFMD is capable of reflecting the natural atmospheric variability of $\mathrm{XCH}_{4}$ as char- acterized by FTIR. WFMD version 0.41 shows up with a break through in data quality relative to version 0.4 due to an a-posteriori time-dependent bias correction, that is based on a channel-8 throughput analysis. However, version 0.41 is still not yet able to capture the natural day-to-day variability on the $\leq 1 \%$ level because the standard deviation calculated from the daily-mean values is $2.4 \%$ using averages within a $2000-\mathrm{km}$ radius, and $2.7 \%$ for a $1000-\mathrm{km}$ radius. We have shown by a merely illustrative (additional) empirical timedependent bias correction, that it is not the precision of the daily means, but the residual time-dependent bias of WFMD v0.41 ( $\approx 3 \% /$ month) what currently limits data quality - and that this can still be improved (e.g., from $2.4 \%$ to $1.6 \%$ by our illustrative empirical time-dependent bias correction). From analysis of the statistics of the individual measurements, we have shown that WFMD data have the potential - as to their pure precision, i.e., neglecting any time-dependent biases to retrieve natural variabilities down to the $0.3 \%$ level for averaging data within a $2000-\mathrm{km}$ selection radius and down to the $0.6 \%$ level for a $1000-\mathrm{km}$ selection radius "if" all systematic type time-dependent drifts would/could be eliminated. This means that the $\mathrm{XCH}_{4}$ annual cycle as well as possibly the atmospheric day-to-day variability could be captured under the prerequisite of further successful advanced time-dependent bias corrections, or the use of other channels, where the icing issue might be less prominent.

Acknowledgements. The authors like to thank A. Rockmann (IMK-IFU) for maintaining the Zugspitze FTIR measurements. Funding by BMBF/DLR as part of the German SCIAMACHY validation program (GCVOS) via contract DLR 50 EE 0007 and by the EC within the project UFTIR (contract EVK2-CT-200200159) is gratefully acknowledged. This work is contributes to the ESA-ENVISAT-Validation-Project TASTE and is part of the EC-Network of Excellence ACCENT-TROPOSAT-2.

Edited by: P. C. Simon

\section{References}

Bovensmann, H., Burrows, J. P., Buchwitz, M., Frerick, J., Noël, S., Rozanov, V. V., Chance, K. V., and Goede, A.: SCIAMACHY Mission Objectives and Measurement Modes, J. Atmos. Sci., 56, 127-150, 1999.

Buchwitz, M. and Burrows, J. P.: Retrieval of $\mathrm{CH}_{4}, \mathrm{CO}$, and $\mathrm{CO}_{2}$ total column amounts from SCIAMACHY near-infrared nadir spectra: Retrieval algorithm and first results, in Proc. SPIE 5235, Remote Sensing of Clouds and the Atmosphere VIII, edited by: Schäfer, K. P., Comeron, A., Carleer, M. R., and Picard, R. H., 375-388, 2004.

Buchwitz, M., de Beek, R., Burrows, J. P., Bovensmann, H., Warneke, T., Notholt, J., Meirink, J. F., Goede, A. P. H., Bergamaschi, P., Körner, S., Heimann, M., Muller, J.-F., and Schulz, A.: Atmospheric methane and carbon dioxide from SCIAMACHY satellite data: initial comparison with chemistry and transport models, Atmos. Chem. Phys., 5, 941-962, 2005a,

SRef-ID: 1680-7324/acp/2005-5-941. 
Buchwitz, M., de Beek, R., Noël, S., Burrows, J. P., Bovensmann, H., Bremer, H., Bergamaschi, P., Körner, S., and Heimann, M.: Carbon monoxide, methane and carbon dioxide columns retrieved from SCIAMACHY by WFM-DOAS: Year 2003 initial data set, Atmos. Chem. Phys. Discuss., 5, 1943-1971, 2005b, SRef-ID: 1680-7375/acpd/2005-5-1943.

Clerbaux, C., Hadji-Lazaro, J., Turquety, S., Megie, G., and Coheur, P.-F.: Trace gas measurements from infrared satellite for chemistry and climate applications, Atmos. Chem. Phys., 3, 14951508, 2003,

\section{SRef-ID: 1680-7324/acp/2003-3-1495}

ESA: Proceedings of the Second Workshop on the Atmospheric Chemistry Validation of ENVISAT (ACVE-2), 3-7 May 2004, ESA-ESRIN, Frascati, Italy, SP-562, ISBN 92-9092-873-5, ESA Publications Division, ESTEC, The Netherlands, 2004.

Hein, R., Crutzen, P. J., and Heimann, M.: An inverse modeling approach to investigate the global atmospheric methane cycle, Global Biogeochem. Cycles, 11, 43-76, 1997.

IPCC, IPCC Third Assessment: Climate Change 2001, The Scientific Basis, Intergovernmental Panel of Climate Change (http://www.ipcc.ch/), 2001.

Kobayashi, H., Shimota, A., Kondo, K., Okumura, E., Kameda, Y., Shimoda, H., and Ogawa, T.: Development and evaluation of the Interferometric Monitor for Greenhouse Gases: a high throughput Fourier transform infrared radiometer for nadir Earth observations, Appl. Opt., 38, 6801-6807, 1999.

Rinsland, C. P., Boughner, R. E., Larsen, J. C., Stokes, G. M., and Brault, J. W.: Diurnal variations of atmospheric nitric oxide: ground-based infrared spectroscopic measurements and their interpretation with time dependent photochemical model calculations, J. Geophys. Res., 89, 9613-9622, 1984.

Rodgers, C. D.: Retrieval of Atmospheric Temperature and Composition From Remote Measurements of Thermal Radiation, Rev. Geophys. Space Phys., 14, 609-624, 1976.
Rodgers, C. and Connor, B. J.: Intercomparison of remote sounding instruments, J. Geophys. Res., 108(D3), 4116, doi:10.1029/2002JD002299, 2003.

Rothmann, L. S., Barbe, A., Benner, D. C., Brown, L. R., CamyPeyret, C., Carleer, M. R., Chance, K., Clerbaux, C., Dana, V., Devi, V. M., Fayt, A., Flaud, J. M., Gamache, R. R., Goldman, A., Jacquemart, D., Jucks, K. W., Lafferty, W. J., Mandin, J. Y., Massie, S. T., Nemtchinov, V., Newnham, D. A., Perrin, A., Rinsland, C. P., Schroeder, J., Smith, K. M., Smith, M. A. H., Tang, K., Toth, R. A., Vander Auwera, J., Varanasi, P., and Yoshino, K.: The HITRAN molecular spectroscopic database: edition of 2000 including updates through 2001, J. Quant. Spectrosc. Radiat. Transfer, 82, 5-44, 2003.

Sussmann, R. and Schäfer, K.: Infrared spectroscopy of tropospheric trace gases: combined analysis of horizontal and vertical column abundances, Appl. Opt., 36, 735-741, 1997.

Sussmann, R.: Ground-based Fourier transform spectrometry at the NDSC site Zugspitze: Geophysical products for satellite validation, in: Proceedings of the European Symposium on Atmospheric Measurements from Space, ESTEC, Noordwijk, The Netherlands, 18-22 Jan 1999, WPP-161, Vol. 2, 661-664, 1999.

Sussmann, R. and Buchwitz, M.: Validation of ENVISAT/SCIAMACHY columnar CO by FTIR profile retrievals at the Ground-Truthing Station Zugspitze, Atmos. Chem. Phys. 5, 1497-1503, 2005,

SRef-ID: 1680-7324/acp/2005-5-1497.

Washenfelder, R. A., Wennberg, P. O., and Toon, G. C.: Tropospheric methane retrieved from ground-based near-IR solar absorption spectra, Geophys. Res. Lett., 30(23), 2226, doi:10.1029/2003GL017969, 2003.

Zander, R., Demoulin, Ph., Ehhalt, D. H., and Schmidt, U.: Secular Increase of the Vertical Column Abundance of Methane Derived from IR Solar Spectra Recorded at the Jungfraujoch Station, J. Geophys. Res., 94, 11 029-11 039, 1989. 